\title{
The Brighter Side of Home Schooling for Children with Special Needs: Learning from COVID-19 Lockdown
}

\author{
Rosna Vincent, R. Nalini and K. Krishnakumar \\ Department of Social Work, Pondicherry University, Puducherry, India \\ https://orcid.org/0000-0002-8509-8814 \\ https://orcid.org/0000-0002-2788-0672 \\ https://orcid.org/0000-0002-5254-9340
}

\begin{abstract}
COVID-19 has resulted in widespread social isolation, quarantines, and suspended academic activity. Children with special needs are socially, financially, and educationally impacted by dramatic changes to laws and restrictions put in place to curtail this devastating global pandemic. This study addresses the beneficial improvements that occurred in the lives of children with special needs during the quarantine period. It led to improved skills, better family dynamics, and an enhancement in technological expertise. Here, we use the case study approach. Twelve parents of children with special needs were selected from the Kozhikode district of Kerala, India. Convenient sampling methods were used for the selection of respondents. The data obtained from the twelve participants were scrutinized. The verbatims were coded with the QDA-Miner Software. Our findings indicate that the lockdown has reinforced family bonds; opened up spaces for homeschooling and digital learning; strengthened relationships with parents, communities, and teachers; and paved the way for technological adaptation. During lockdown, children with special needs continued to learn and build skills in a nurturing familial environment.
\end{abstract}

Keywords: children with special needs; home-schooling; digital learning; COVID-19 lockdown

\section{Introduction}

The infectious nature of COVID-19 has profoundly impacted daily life by imposing social distancing, quarantine, academic shutdown, and other precautions to prevent the spread of the pandemic (Viner et al., 2020). It instituted dramatic changes in everyday life that culminated in distinct realms, such as family, education, and work-life. Prior studies have shown that lockdowns harm the lives of students (Asbury et al., 2020; Bonal \& González, 2020; Rajmil et al., 2021; Thakur, 2020). Access to programmes for people with 
disabilities has been seriously disrupted by COVID-19 restrictions (Jeste et al., 2020; Shetty et al., 2020). Sudden adoption of precautionary measures and other environmental constraints and pandemic-related contextual variables have a disproportionate effect on the lives of children with special needs. They have been socially, financially and educationally disadvantaged (Alexander et al., 2020; Narvekar Hemangi Narayan, 2020; WHO, 2020). As per the 2011 Census of India, about 26.8 million individuals are 'disabled' out of the 1.21 billion population in India, which is $2.21 \%$ of the total population of the country and the prevalence rate of children suffering from acute disability is $1.24 \%$ (Ministry of Statistics and Programme Implementation, 2016). COVID-19 instituted a new schedule for kids with special needs. They no longer have access to places they enjoyed, friends, playtime or the ability to participate in activities they aspired for. In children with special needs, these have led a sense of desperation (Provenzi et al., 2020; Unni, 2020). Further, because of their health-related limitations and failure to understand and obey prescribed infection control steps, children with special needs are at greater risk of exposure to COVID-19 (Cuypers et al., 2020; Juneja \& Gupta, 2020).

COVID-19 has also created a traumatic experience for parents of children with special needs, including physical and economic security; anxiety about the social isolation of children from peers and teachers. This left them anxious about the management, extent, and effectiveness of residential care (Aishworiya \& Kang, 2020; Fontanesi et al., 2020). Sudden lockdown forced parents to play several roles at home (Rose et al., 2020); it urged them to synchronously be a coach, therapist, and caregiver. Many caretakers are in a dilemma because they are not aware of the methods and the application to produce the desired results (Dhiman et al., 2020).

Nonetheless, the lockdown also had some positive outcomes in the lives of these children (Cahapay, 2020; Majoko \& Dudu, 2020). For many, staying at home provided a sense of protection, allowed them to spend time in a relaxed manner, and was a necessity for maintaining a level of safety in the community (Bozdağ, 2020). It allowed families to bond together over more family time (Toquero, 2021). Our research assessed the beneficial changes that happened in the lives of these children, including improvements in skills, family relationships, and improved technical knowledge.

\section{Literature Review}

Special education research has made a substantial contribution to knowledge and practice for all learners, not just to those with challenges (Vaughn \& Swanson, 2015). Children with specific needs require more assistance, a personalized approach, and adapted lessons to continue learning at home throughout the COVID-19 phase (Narvekar, 2020).

According to a study conducted among mothers of children with intellectual disabilities, some have spoken about the positive influence of the lockdown situations on their well-being and that of their child. However, most of the mothers have stated the opposite, suggesting that the impact of the lockdown was actually detrimental to their child's well-being and behaviour. The study 
further states that recent COVID-19 lockdown restrictions have resulted in children with intellectual disabilities and their caregivers having less access to educational, professional, and social support systems (Rogers et al., 2021).

A study conducted in seven European countries found that many parents experienced a range of negative outcomes for themselves and their kids due to homeschooling, and a substantial number felt that homeschooling was lacking in quality, with schools providing insufficient support. In almost every country, contact with teachers was limited, leaving parents solely responsible for supervising the homeschooling of their children (Thorell et al., 2021).

A study among Norwegian students reported that teachers offered less verbal input to pupils during homeschooling and offered a higher volume of written feedback compared to when they were in the classroom in the conventional school setting. In addition, low-achieving children exhibited lowered selfefficacy and a decreased willingness to make an effort, which will make it harder to change when schools reopen (Mælan et al., 2021).

Cahapay (2020) offers a detailed look at how parents of autistic children homeeducate their offsprings in the COVID-19 period. The interviews of five parents were carried out using a mostly qualitative research approach. The findings of this study underscore the importance of different kinds of home-schooling. and sheds light on strategies to educate children with autism (Cahapay, 2020)

A research study from Zimbabwe examined the techniques adopted by parents to educate their children with Autism spectrum disorder (ASD) during the COVID-19 period. The balancing and additional roles of parents and family members in children's home education helped to ease the changeover of children with ASD from school to habitual activities at home. An understanding of the new social dynamics of the COVID-19 era, as well as security precautions, were instilled in the children (Majoko \& Dudu, 2020).

Daulay (2021) calls for appropriate coping methods to assist mothers in easing the difficulties associated with adopting home education and the stress associated with parenting. The study found that the adoption of home schooling during the pandemic was less than ideal due to an increase in autistic children's maladaptive behaviours, low adaptability, the difficulty of caregiving, and rising negative emotions (Daulay, 2021).

\section{Methodology}

\subsection{Research type}

The qualitative research approach and case study method were employed in this study. In-depth multi-faceted investigations of complicated issues in real-life settings are enabled by the case study approach, which was found to be ideal for this study as its objective was to explain the brighter side of home-based education due to lockdown for children with special needs.

\subsection{Research participants}

A sample of twelve parents (eleven mothers and one father) of children with special needs was recruited from a special school in Kozhikode district, Kerala. 
Kerala State in southern India boasts the highest life expectancy, literacy, and low infant mortality rates in the third world while being one of the lowest per capita incomes. The convenient sampling technique was adopted for respondent selection. The procedure of case selection involved the selection of 'Typical cases', as identified by the researchers. The inclusion criteria of the participants were: having a child with special needs who was attending special school minimum four days in a week before the lockdown; internet and cell phone access; and staying with own child during the COVID-19 lockdown

\subsection{Data gathering tools}

An open-ended semi-structured interview guide was used in this study. We developed the interview guide following on extensive review of the literature and from our field work experience. The interview guide was vetted by an expert in special education for scrutiny, and then the reframed questions were trial-tested on three parents. The trial interview allowed us to identify any gaps. The interview guide was further revised and was given to an expert in social work for further scrutiny. After incorporating final suggestions, the interview guide was employed for data collection.

Data were collected from January to February 2021, when the number of active cases of COVID-19 declined in India and people were beginning to start a new normal life. This timeframe allowed the respondents to recollect the experiences of lockdown at home and enabled them to recognize the changes that have arisen in children with intellectual disabilities in the home setting. Due to COVID-19 limitations, individual interviews were performed by telephone. Telephonic interviews provide participants with the opportunity to communicate their feelings or thoughts about a phenomenon being investigated (Seidman, 2006). At least two telephone calls were made by the researcher, first to convey the intent of the present study and schedule a comfortable time for the interview. The second call was made to collect the required data for the study. Informed consent was obtained from all the subjects. Informed consent, anonymity, confidentiality, and the freedom of participants to withdraw from the study at any time were guaranteed to all the participants.

Each interview, on average, lasted slightly more than an hour. The respondents were interviewed until data saturation was observed. By the twelfth interview, data saturation was reached and therefore data collection stopped. The information derived from the twelve participants was analyzed. The verbatims were coded with the QDA Miner Software, a computer application for mixed methods and qualitative data analysis developed by Provalis Research (LaPan, 2013). The main themes were familial bonding, home-based learning, parent to tutor and parent to parent relationships and technological adaptation. The verbatim excerpts which are best exemplars from the interviews are presented at times. 


\section{Results}

Table 1: Demographic features of families having children with special needs

\begin{tabular}{cclcl}
\hline Parents code & Age & Occupation & Age of the child & Gender of the child \\
\hline 1. & 39 & Self-employed & 11 & Female \\
\hline 2. & 40 & Teacher & 13 & Female \\
3. & 41 & $\begin{array}{l}\text { Government } \\
\text { Employee }\end{array}$ & 12 & Male \\
& & & \\
4. & 36 & Private employee & 8 & Male \\
\hline 5. & 42 & Engineer & 14 & Male \\
6. & 48 & Business & 16 & Male \\
\hline 7. & 43 & Homemaker & 13 & Male \\
\hline 8. & 44 & Homemaker & 13 & Female \\
9. & 42 & Private employee & 13 & Male \\
10. & 45 & Designer & 12 & Female \\
\hline 1. & 44 & Homemaker & 15 & Female \\
\hline 12. & 45 & Teacher & 16 & Male \\
\hline
\end{tabular}

Through the data analysis, several themes about the positive developments that happened among children with special needs during COVID-19 lockdown were identified and are described and discussed below (Table 2).

Table 2: Themes and Participants' statement

\begin{tabular}{lll}
\hline Themes & Subthemes & Supporting statements \\
\hline Familial & $\begin{array}{l}\text { Stay Together } \\
\text { Shared } \\
\text { Responsibilities }\end{array}$ & $\begin{array}{l}\text { Only due to which we had a lot of moments together } \\
\text { during the lockdown. }\end{array}$ \\
& $\begin{array}{l}\text { My husband was available at home he started } \\
\text { assisting me in household chores like cooking food } \\
\text { for the family, washing clothes } \\
\text { Relation }\end{array}$ & $\begin{array}{l}\text { Most of the time, my child spent time talking to } \\
\text { ammumma [Grandma]. She learnt a lot of new things } \\
\text { from ...both my child and ammumma [Grandma] } \\
\text { became very happy due to lockdown. }\end{array}$ \\
& $\begin{array}{l}\text { Now he spent all his time with H. They became more } \\
\text { friends than ever before. Z is now doing all the } \\
\text { things for his brother }\end{array}$ \\
&
\end{tabular}

Home-Based Learning Learning through Games

Home-Based

Routine

Skills

Acquisition
She learnt to play the game after few days... She is also recognizing colors now.

Before lockdown, my child had a very disturbed routine... But lockdown made her more adjusted with the life at home... She started adapting to the home environment... Now she is having a better routine than before. 
He started painting the bottles with his brother. The beautification of this house with crafts was completed by the efforts of $\mathrm{J}$, and his brother.

\begin{tabular}{lll}
$\begin{array}{l}\text { Parent to } \\
\text { tutor and } \\
\text { parent to } \\
\text { parent } \\
\text { relationship }\end{array}$ & $\begin{array}{l}\text { Parent to } \\
\text { Teacher } \\
\text { Relationship }\end{array}$ & $\begin{array}{l}\text { I use to complain always that the teaching is not } \\
\text { adequate...but now I understand the real value of a } \\
\text { special educator and the efforts she takes when I } \\
\text { became a part of the classes. }\end{array}$ \\
$\begin{array}{l}\text { Parent to Parent } \\
\text { Relationship }\end{array}$ & $\begin{array}{l}\text { Another child's mother actually helped me in } \\
\text { learning mobile for online class...she is my greatest } \\
\text { support. She loves my child as her child }\end{array}$ \\
$\begin{array}{l}\text { Technological } \\
\text { Adaptation }\end{array}$ & Online class & $\begin{array}{l}\text { I use to call the special educator frequently, but now I } \\
\text { learnt how to effectively involve in an online class } \\
\text { with my child. }\end{array}$ \\
& Typing skill & $\begin{array}{l}\text { My child is able to identify alphabets on the } \\
\text { keyboard... }\end{array}$ \\
& Video calling & $\begin{array}{l}\text { He knows how to open video calling, different } \\
\text { modes in it... I am just learning only }\end{array}$ \\
\hline
\end{tabular}

\subsection{Theme 1: Familial Bonding}

The most significant theme in this study was familial bonding. This was an opportunity for the families to stay together and enforce unity which in turn, intensified bonds between family members. Increased parental care led to happier children and better developmental performance in children with special needs. Parents, who normally worked long hours and saw little of their kids, welcomed the opportunity provided by the lockdown to work from home and establish deeper ties with their children. Time with family seems to build a positive state of mind in children with special needs as it can raise their level of happiness while being in the presence of individuals who offer unconditional love. Moreover, spending precious time with loved ones will create memories that everyone will cherish for a lifetime.

"I was scared about the school closure due to Corona but I was happy to know that my office was also closed... Only due to which we had a lot of moments together during the lockdown." (Parent 3, Govt. Employee)

"I was having a very busy life, the pandemic made me sit at home... Loving my child all the time, it never happened till date, it was actually a blessing for us." (Parent 6, Business)

"I am happy that I was able to dine with her all four times for many months..." (Parent 10, Designer)

For parents, lockdown is an opportunity to spend more time at home with their children. The freedom to work from home have contributed to a reassessment of work and job goals. Parents are actively seeking stronger family and personal 
ties, as well as a better work-life balance. They are searching for more flexible working schedules in the future so that they can spend longer with their children with special needs and rely less on institutionalized childcare.

"During lockdown...... noticed that, child became more happy due our companionship all the time.. Overall there was a great change in his behaviour.....actually now we are realizing... We must allocate more time for our child...we are planning to make our working hours more flexible after lockdown" (Parent 1, Self-employed)

"I feel guilty that I used to spend very little time with my child... lockdown made me rethink about my working hours.... will certainly spend more time with my child..." (Parent 2, Teacher)

The outcomes of this study also suggest that the number of hours fathers spent with their children has increased significantly. Re-evaluation of fatherhood can have a major effect in the changes of children with special needs. The gender care gap appears to be decreasing, though mothers still have more parenting roles. As men stayed at home for the whole day, the idea women are solely responsible for child care and the housework seems to be fading away. This change would not only make parenting more manageable during the lockdown but also enhance familial relationships.

"Earlier my husband had very little time to care for the needs of the child.... ... Lockdown was a time when I witnessed how deep is fatherly love.... He spent all the time with the child and cared for him round the clock....now X needs father all the time, more than me" (Parent 4, Pvt. Employee)

"I was engaged with activities like online learning, it takes lots of time....as my husband was available at home he started assisting me in household chores like cooking food for the family, washing clothes etc" (Parent 3, Govt. Employee)

It has also been noted that intergenerational contact in recent months has increased. COVID-19 Pandemic has made grandparents more likely to spend much more time with their grandchildren. It helped grandchildren to be more emotionally committed to their grandparents. This would raise levels of communication and increased comprehension of the needs of children with special needs among their grandparents.

"After all of us goes for work and Y goes to school, Ammumma (Grandmother) is alone at home. Now she became very happy that all members of the family are at home...most of the time, my child spent time talking to ammumma. She learnt a lot of new things from ...both my child and ammumma became very happy due to lockdown..." (Parent 5, Engineer)

The lockdown isolated children with special needs from their peers, teachers, and from the school environment in which they have been socializing since they were young. Many children with special needs' siblings spent more time with friends and colleagues than their family. Now, everyone is at home. The siblings are also relieved of duties of work or school. It was noted that in this phase of 
lockdown siblings invested greater affection and more time for care and support of their brother or sister with special needs.

" $Z$ never spent time with $X$ before lockdown....he never sits at home, is busy always.... roaming with his friends here and there...but now he spent all his time with $H$. They became more friends than ever before. $Z$ is now doing all the things for his brother.......he is the only person whom I can rely upon...own blood... I feel very happy that my child will be cared by his brother, even after god calls me..." (Parent 7, Homemaker)

COVID lockdown has created close sibling bonds with noticeable positive emotional impacts on both siblings.

\subsection{Theme 2: Home-based learning}

Home is a safe and welcoming setting where one can be free of the doubt and assumptions of others. The research demonstrated that for many children with special needs, spending more time with their families had advantageous impacts. Parents believed that their children benefited from one-on-one instruction at home, contributing to progression in their abilities, contrary to some of the negative accounts of homeschooling. When children were not able to attend special schools, many parents invented new ways to spend play time at home. We noticed that children with special needs were more interested in playing games with family members.

"We started playing some card games during corona....she learnt to play the game after few days... She is also recognizing colours now..." (Parent 8, Homemaker)

"He learned to flip a stone in the river...his elder brother use to do that frequently and he learnt from him" (Parent 9, Private Employee)

Most notably, children were able to build a daytime home-based routine that never existed when they were sent to special schools. The children also began to help their parents do simple house chores collectively. The development of a home-based routine is rated as one of the best achievements of lockdown life by many parents.

"Earlier, my child was not able to maintain the table manners... But, now all we were having food together. He has improved a lot in table manners..." (Parent 3, Government Employee)

"Before lockdown, my child had a very disturbed routine... But lockdown made her more adjusted with the life at home... She started adapting to the home environment... Now she is having a better routine than before." (Parent 11, Homemaker)

The home environment and the presence of family members help the children with special needs to acquire new skills. These skills exposed many inborn talents of children with special needs. Children were reported to have engaged in activities such as bed making, watering plants, washing vegetables etc. Children also started doing some gardening activities along with their parents during the lockdown period. 
"He started painting the bottles with his brother... The beatification of this house with crafts was completed by the efforts of J, and his brother..." (Parent 12, Teacher)

"K started assisting me in washing clothes" (Parent 9, Private Employee)

Overall, these progress were a result of one-to-one learning in at-home environment. This skill-building seems to be very important effect of lockdown.

\subsection{Theme 3: Parent to tutor and parent to parent relationship}

The pandemic really helped in strengthening the ties between parents and teachers. Till date, there was limited parental involvement in educating special children. However, this pandemic brought the teaching community more closely to the parents. The new normal prompted both parents and teachers to work for shared goals. Some parents responded that from the culture of individuals who complain about each other, the parents and teachers have now come to a mutual understanding to work towards a common objective.

"I use to complain always that the teaching is not adequate...but now I understand the real value of a special educator and the efforts she takes when I became a part of the classes" (Parent 6, Business)

"Teachers told that we are partners in the teaching of our children...without our cooperation, teaching is not possible during this corona time" (Parent 9, Private Employee)

The parents were able to succeed in making specific goals and plans with the help of teachers in the education of the children with special needs. Both planning and execution of ideas happened with a thorough discussion with the educators and the parents.

"We along with the teachers of the school make a plan of action every week, so we know, on which day what are the activities to be done, at what time we will meet online..."(Parent 4, Pvt. Employee)

"Teachers ask us at least a day before giving any activity to children next day..." (Parent 11, Homemaker)

Parents also reported that the teachers started allocating a particular time to meet with them regularly online to assess the children's progress. Thus, the teachers were able to keep track of their students by collaborating with the parents in the process of educating the children away from the special school. These online meetings served as a platform to discuss the special needs of the children in detail. Thus, through online meetings, WhatsApp chats, small text messages, parents were made partners in special education. All these are shared as a positive experience by almost all the respondents in this study.

"The teachers ask for feedback about the programmes done, is there any improvement, what all changes need to make..." (Parent 1, Selfemployed)

"The teacher always put messages in WhatsApp group .... All the parents including me also put their comments in the group" (Parent 7, Homemaker) 
The pandemic also improved the relationships with the parent community. The parents started working along with the teachers in the special education process. The parents of children with special needs who were not connected till date were united by the pandemic.

"Another child's mother actually helped me in learning mobile for online class...she is my greatest support... She loves my child as her child" (Parent 5, Engineer)

"Parents of other children became more familiar as we are all meeting daily online" (Parent 12, Teacher)

The parents supported each other by adjusting work schedules and other life engagements during the pandemic period which were facilitated by the community of special educators. Many parents hope that this connection would continue even after the pandemic.

\subsection{Theme 4: Technological adaptation}

The education system has undergone a significant digital transformation to address the needs of children with special needs. One of the positive advances during the lockdown was technological adaptation. The parents as well as their children became more familiar with various e-learning resources. The online instruction prompted many parents to adopt new technologies and features to help their children in learning.

"I thought that classes will soon be opened... But then I understood that it will not in the near future, my problem was.... the mobile phone was old. So for the online class, I bought a new tab with more features....." (Parent 1, Self-employed)

In many schools, initial orientation programmes were conducted for the parents in making them acquainted with the online learning process. The parents of children with special needs also mutually supported each other during the initial skill acquirement process. In certain cases, special educators and technical experts assigned by the special schools made home visits to familiarize parents with the technology.

"School organized a class for us regarding the effective participation in online classes... During the beginning of online classes, I had lots of doubts....I use to call the special educator frequently... But now I learnt how to effectively involve in an online class with my child..." (Parent 3, Govt. Employee)

The children too have acquired new skills. For many children, it was a happy experience to meet their teachers and friends online. When days went on, the children became more familiar with the use of technology. Many children learnt how to operate programmes in mobile phones and open video calls. The children were also able to understand the operating procedures of devices such as camera, headphones, and keyboard.

"My child is able to identify alphabets on keyboard..." (Parent 4, Private Employee)

"He knows how to open video calling, different modes in it. I am just learning only" (Parent 6, Business) 
Technology has paved the way for one-to-one learning which seems to be of very positive effect for children with special needs.

\section{Discussion}

In this study, we discussed the brighter side of the COVID-19 lockdown among families with children with special needs. Contrary to the findings of studies conducted among parents outside India, which emphasized that COVID-19 contributes to parenting stress and adversely affected parenting outcomes (Chung et al., 2020), we found that parental care increased for children with special needs during the lockdown and made children happier which led to better development. Findings from this study have shown that the lockdown was an incentive for many parents to spend more time with their children; the ability to work from home contributed to a re-evaluation of career and career ambitions. A study conducted among parents documented a similar outcome, which showed that lockdown allows families to build togetherness among family members, children continued to make developmental progress, and adapted to being at home (Neece et al., 2020).

We also show that there has been a substantial increase in the number of hours fathers spend with their children. In the care of children with special needs, reevaluation of fatherhood may have a significant impact. It appears that the gender care gap is diminishing. Studies conducted among parents have stressed on the fact that positive interactions in relationships between parents were positively correlated with empathic concern and outlook in both parents and children (Gambin et al., 2020). It has also been noted that intergenerational interaction has risen significantly. We found positive intergenerational contacts and a positive correlation for arrangements for the care of grandchildren by grandparents (Arpino et al., 2020). Although previous studies have portrayed that the pandemic of COVID-19 harms the sibling subsystem due to pandemicrelated stress factors (Prime et al., 2020), we documented a positive relationship between siblings and children with special needs during the lockdown.

A significant number of parents thought that one-to-one training at home was good for their children. Research conducted by parents of children with special needs has shown that one-to-one home environment training is beneficial and enhances aspects of adaptive behaviour (Shin et al., 2009). We showed that children with special needs were more excited to play board games and video games with family members. After the pandemic, families tend to spend more time together, walk, play and finish tasks. When time is available, caregivers need to socialize with children through plays, handicrafts and music. Sharing time with children can be achieved by watching TV shows or using educational software with a caregiver's assistance (Goldschmidt, 2020).

More notably, there is a rising willingness from children's part to develop a personal routine, which they have never done before in environments where they were sent for special education. Kids have developed a standard home routine by being at home for an extended period (Neece et al., 2020). 
According to some studies, the pandemic crisis made children with special needs lose the opportunity to learn new skills because of a pause in therapy sessions, school closures etc. (Lee, 2020). However, the parents interviewed in this study ascertain that their children had an unusual growth in their abilities while they were at home. Other studies also shed light on the fact that during the pandemic, parents saw it as an opportune time to teach their children basic skills (Cahapay, 2020).

We found that the teaching community came closer to parents after the pandemic. Close parent-teacher-student relationships are important for better learning outcomes (Segal, 2010). The parents and teachers did an outstanding job in setting and implementing realistic goals and objectives with relation to the children's education. We found that when parents indicated that their children didn't receive adequate teacher contact, the online learning process suffered (Garbe et al., 2020). Not only did the pandemic strengthen the ties with the parent group, but it also helped with relationships with the children in the community. An investigation among parents in Zimbabwe during COVID-19 found that parent-to-peer parent relationships strengthened, creating an opportunity to form home-grown methods for successful behaviour management and to acculturate children with special needs (Majoko \& Dudu, 2020). It is important to maintain online contact with other stakeholders, including other parents, educators, caregivers and therapists, to communicate and gain different forms of support needed to continuing home-schooling young people with special educational needs (Narzisi, 2020).

The technical adaptation was one of the positive developments during the lockdown. An in-depth review of current studies was undertaken to determine the efficacy of different technologies for children with Autism Spectrum disorder. The review discovered that both children and caregivers enjoyed using technologies like online schooling, tele-health, screening, and evaluation (Dahiya et al., 2021). During the pandemic era, children became more familiar with diverse e-learning resources. Due to the transition from face-to-face to virtual learning, the comparable result was shared by a study that the pandemic prompted children to recognise and familiarize themselves with different elearning opportunities and made education based on learners more flexible (Dhawan, 2020). Initial orientation sessions for parents and teachers have been held in many schools to familiarize them with the online learning process. Studies have suggested that teachers must be prepared before beginning online education because of the suspension of face-to-face classes (Moorhouse, 2020). The children learnt new skills, too. The study conducted among children with Autism found that new skills were built from the struggles during the pandemic (Cahapay, 2020).

For many children, meeting new friends and teachers online was a wonderful experience. Online learning is cost-effective, because it eliminates travel and other expenses needed for in-person courses. It is a convenient way for participants to interact with each other and with teachers because learners do not have to meet face-to-face (Kim, 2020). E-resources were made available by the educators. Online learning in India shed light on online learning 
opportunities and techniques that are designed to allow learners to continue their education (Jena, 2020). It is reported that only $6 \%$ of teachers considered streaming YouTube and Facebook as a means of digital classrooms however, a significant percentage of students have depended upon YouTube and Facebook for video lectures (Mishra et al., 2020).

\section{Conclusion}

The contagious state of COVID-19 has drastically altered daily life across the globe, with a whole array of disruptive implications, including quarantines, closures, mandatory rest, and other measures to contain the epidemic. Numerous research studies have shown that lockdown disrupts the pupils' quality of life and academic environment. However, this paper focused on the brighter side of the lockdown among the families of children with special needs. The results underscore the following themes: (1) familial bonding; (2) homebased learning; (3) parent to tutor and parent to parent relationship; and (4) technological adaptation. Though restricted within a certain context and a small sample, this work presents a glimpse into the home education of children with special needs amid the impacts of the current global crisis. These types of interventions have the potential to significantly improve the efficacy of online learning. Recognizing the crucial role that parents, students, and teachers play in the aftermath of school closures, governments should use administrative measures to facilitate their effective involvement. Both parents and instructors can help their children to effectively limit the obstacles of 'at home learning': parents can give emotional and educational support, while teachers may act as mentors, promoting active learning and motivation while ensuring that no child is left behind (OECD, 2020). Only the positive aspects of home schooling were investigated in this study. Additionally, doing research during the pandemic time posed a larger difficulty. This study consisted of a small number of participants and relied primarily on a qualitative assessment. Involving more number of respondents and using the mixed method strategy may bring up all the good and bad impacts of home-schooling for children with special needs.

\section{Acknowledgement}

The authors specially thank all the participants of the study. The authors are grateful to the services of Special school teachers who helped in the successful conduct of this study. Although no funds were allocated specifically for this research study, the first author and third author thank University Grants Commission, New Delhi for providing Junior/Senior Fellowships for their doctoral researches.

\section{References}

Aishworiya, R., \& Kang, Y. Q. (2020). Including Children with Developmental Disabilities in the Equation During this COVID-19 Pandemic. Journal of Autism and Developmental Disorders, 0123456789, 1-4. https://doi.org/10.1007/s10803020-04670-6

Alexander, R., Ravi, A., Barclay, H., Sawhney, I., Chester, V., Malcolm, V., Brolly, K., Mukherji, K., Zia, A., Tharian, R., Howell, A., Lane, T., Cooper, V., \& Langdon, P. E. (2020). Guidance for the Treatment and Management of COVID-19 Among People with Intellectual Disabilities. Journal of Policy and Practice in Intellectual Disabilities, 17(3), 256-269. https:// doi.org/10.1111/jppi.12352 
Arpino, B., Bordone, V., \& Pasqualini, M. (2020). No clear association emerges between intergenerational relationships and COVID-19 fatality rates from macro-level analyses. Proceedings of the National Academy of Sciences of the United States of America, 117(32), 19116-19121. https:// doi.org/10.1073/pnas.2008581117

Asbury, K., Fox, L., Deniz, E., Code, A., \& Toseeb, U. (2020). How is COVID-19 Affecting the Mental Health of Children with Special Educational Needs and Disabilities and Their Families? Journal of Autism and Developmental Disorders, 0123456789. https://doi.org/10.1007/s10803-020-04577-2

Bonal, X., \& González, S. (2020). The impact of lockdown on the learning gap: family and school divisions in times of crisis. International Review of Education, 66(5-6), 635655. https://doi.org/10.1007/s11159-020-09860-z

Bozdağ, F. (2020). The psychological effects of staying home due to the COVID-19 pandemic. Journal of General Psychology, 0(0), 1-23. https://doi.org/10.1080/00221309.2020.1867494

Cahapay, M. B. (2020). How Filipino parents home educate their children with autism during COVID-19 period. International Journal of Developmental Disabilities, 3869. https:// doi.org/10.1080/20473869.2020.1780554

Chung, G., Lanier, P., \& Wong, P. Y. J. (2020). Mediating Effects of Parental Stress on Harsh Parenting and Parent-Child Relationship during Coronavirus (COVID-19) Pandemic in Singapore. Journal of Family Violence. https://doi.org/10.1007/s10896-020-00200-1

Cuypers, M., Schalk, B. W. M., Koks-Leensen, M. C. J., Nägele, M. E., Bakker-van Gijssel, E. J., Naaldenberg, J., \& Leusink, G. L. (2020). Mortality of people with intellectual disabilities during the 2017/2018 influenza epidemic in the Netherlands: potential implications for the COVID-19 pandemic. Journal of Intellectual Disability Research, 64(7), 482-488. https://doi.org/10.1111/jir.12739

Dahiya, A. V., DeLucia, E., McDonnell, C. G., \& Scarpa, A. (2021). A systematic review of technological approaches for autism spectrum disorder assessment in children: Implications for the COVID-19 pandemic. Research in Developmental Disabilities, 109(December 2020), 103852. https:// doi.org/10.1016/j.ridd.2021.103852

Daulay, N. (2021). Home education for children with autism spectrum disorder during the COVID-19 pandemic: Indonesian mothers experience. Research in Developmental Disabilities, 114, 103954. https://doi.org/10.1016/j.ridd.2021.103954

Dhawan, S. (2020). Online Learning: A Panacea in the Time of COVID-19 Crisis. Journal of Educational Technology Systems, 49(1), 5-22. https://doi.org/10.1177/0047239520934018

Dhiman, S., Sahu, P. K., Reed, W. R., Ganesh, G. S., Goyal, R. K., \& Jain, S. (2020). Impact of COVID-19 outbreak on mental health and perceived strain among caregivers tending children with special needs. Research in Developmental Disabilities, 107(17), 103790. https://doi.org/10.1016/j.ridd.2020.103790

Fontanesi, L., Marchetti, D., Mazza, C., Di Giandomenico, S. D., Roma, P., \& Verrocchio, M. C. (2020). The Effect of the COVID-19 Lockdown on Parents: A Call to Adopt Urgent Measures. Psychological Trauma: Theory, Research, Practice, and Policy, 12, 79-81. https://doi.org/10.1037/tra0000672

Gambin, M., Woźniak-Prus, M., Sękowski, M., Cudo, A., Pisula, E., Kiepura, E., Boruszak-Kiziukiewicz, J., \& Kmita, G. (2020). Factors related to positive experiences in parent-child relationship during the COVID-19 lockdown. The role of empathy, emotion regulation, parenting self-efficacy and social support. The Role of Empathy, Emotion Regulation, 4(1). https://doi.org/10.31234/osf.io/yhtqa 
Garbe, A., ogurlu, U., Logan, N., \& Cook, P. (2020). Parents' Experiences with Remote Education during COVID-19 School Closures. American Journal of Qualitative Research, 4(3), 45-65. https://doi.org/10.29333/ajqr/8471

Goldschmidt, K. (2020). The COVID-19 Pandemic: Technology use to Support the Wellbeing of Children. Journal of Pediatric Nursing, 53(xxxx), 88-90. https:// doi.org/10.1016/j.pedn.2020.04.013

Jena, P. K. (2020). Online Learning During Lockdown Period For Covid-19 In India. International Journal of Multidisciplinary Educational Research (IJMER), 514(5), 8292. https://doi.org/10.31235/osf.io/qu38b

Jeste, S., Hyde, C., Distefano, C., Halladay, A., Ray, S., Porath, M., Wilson, R. B., \& Thurm, A. (2020). Changes in access to educational and healthcare services for individuals with intellectual and developmental disabilities during COVID-19 restrictions. Journal of Intellectual Disability Research, 64(11), 825-833. https://doi.org/10.1111/jir.12776

Juneja, M., \& Gupta, A. (2020). Managing Children with Special Needs in COVID-19 Times. Indian Pediatrics, 57(10), 971. https:/ / doi.org/10.1007/s13312-020-2009-1

Kim, J. (2020). Learning and Teaching Online During Covid-19: Experiences of Student Teachers in an Early Childhood Education Practicum. International Journal of Early Childhood, 52(2), 145-158. https://doi.org/10.1007/s13158-020-00272-6

LaPan, C. (2013). Review of QDA Miner. Social Science Computer Review, 31(6), 774-778. https://doi.org/10.1177/0894439313492711

Lee, J. (2020). Mental health effects of school closures during COVID-19. The Lancet Child and Adolescent Health, 4(6), 421. https://doi.org/10.1016/S2352-4642(20)30109-7

Mælan, E. N., Gustavsen, A. M., Stranger-Johannessen, E., \& Nordahl, T. (2021). Norwegian students' experiences of homeschooling during the COVID-19 pandemic. European Journal of Special Needs Education, 36(1), 5-19. https://doi.org/10.1080/08856257.2021.1872843

Majoko, T., \& Dudu, A. (2020). Parents' strategies for home educating their children with Autism Spectrum Disorder during the COVID-19 period in Zimbabwe. International Journal of Developmental Disabilities. https:// doi.org/10.1080/20473869.2020.1803025

Ministry of Statistics and Programme Implementation. (2016). Disabled persons in India: A statistical profile. $0-107$. http://mospi.nic.in/sites/default/files/publication_reports/Disabled_persons_ in_India_2016.pdf

Mishra, L., Gupta, T., \& Shree, A. (2020). Online teaching-learning in higher education during lockdown period of COVID-19 pandemic. International Journal of $\begin{array}{llll}\text { Educational Research } & \end{array}$ https://doi.org/10.1016/j.jedro.2020.100012

Moorhouse, B. L. (2020). Adaptations to a face-to-face initial teacher education course 'forced' online due to the COVID-19 pandemic. Journal of Education for Teaching, 46(4), 1-3. https://doi.org/10.1080/02607476.2020.1755205

Narvekar, H. N. (2020). Educational concerns of children with disabilities during COVID-19 pandemic. In Indian Journal of Psychiatry (Vol. 62, Issue 5, pp. 603604). Wolters Kluwer Medknow Publications. https://doi.org/10.4103/psychiatry.IndianJPsychiatry_585_20

Narvekar Hemangi Narayan. (2020). Educational concerns of children with disabilities during COVID-19 pandemic. Indian Journal of Psychiatry, 62(5), 603-604. https:// doi.org/10.4103/psychiatry.IndianJPsychiatry

Narzisi, A. (2020). Handle the autism spectrum condition during coronavirus (Covid-19) stay at home period: Ten tips for helping parents and caregivers of young 
children. Brain Sciences, 10(4), 10-13. https://doi.org/10.3390/brainsci10040207

Neece, C., McIntyre, L. L., \& Fenning, R. (2020). Examining the impact of COVID-19 in ethnically diverse families with young children with intellectual and developmental disabilities. Journal of Intellectual Disability Research, 64(10), 739749. https://doi.org/10.1111/jir.12769

OECD. (2020, September 24). Strengthening online learning when schools are closed: The role of families and teachers supporting students during the COVID-19 crisis. https:/ / read.oecd-ilibrary.org/view/?ref=136_136615-

o13x4bkowa\&title=Strengthening-online-learning-when-schools-areclosed\&_ga =2.172304171.92291282.1626496035-639922686.1607534103

Prime, H., Wade, M., \& Browne, D. T. (2020). Risk and resilience in family well-being during the COVID-19 pandemic. American Psychologist, 75(5), 631-643. https:// doi.org/10.1037/amp0000660

Provenzi, L., Grumi, S., \& Borgatti, R. (2020). Alone With the Kids: Tele-Medicine for Children With Special Healthcare Needs During COVID-19 Emergency. Frontiers in Psychology, 11(September), 1-6. https://doi.org/10.3389/fpsyg.2020.02193

Rajmil, L., Hjern, A., Boran, P., Gunnlaugsson, G., Kraus De Camargo, O., \& Raman, S. (2021). Impact of lockdown and school closure on children's health and wellbeing during the first wave of COVID-19: A narrative review. In BMJ Paediatrics Open (Vol. 5, Issue 1). BMJ Publishing Group. https://doi.org/10.1136/bmjpo2021-001043

Rogers, G., Perez-Olivas, G., Stenfert Kroese, B., Patel, V., Murphy, G., Rose, J., Cooper, V., Langdon, P. E., Hiles, S., Clifford, C., \& Willner, P. (2021). The experiences of mothers of children and young people with intellectual disabilities during the first COVID-19 lockdown period. Journal of Applied Research in Intellectual Disabilities, 00(1), 1-10. https://doi.org/10.1111/jar.12884

Rose, J., Willner, P., Cooper, V., Langdon, P. E., Murphy, G. H., \& Stenfert Kroese, B. (2020). The effect on and experience of families with a member who has Intellectual and Developmental Disabilities of the COVID-19 pandemic in the UK: developing an investigation. International Journal of Developmental Disabilities, 1-3. https://doi.org/10.1080/20473869.2020.1764257

Segal, D. L. (2010). Diagnostic and Statistical Manual of Mental Disorders (DSM-IV-TR). The Corsini Encyclopedia of Psychology, January 2010. https://doi.org/10.1002/9780470479216.corpsy0271

Seidman, I. (2006). Interviewing as Qualitative Research: A Guide for Researchers in Education and the Social Sciences (3rd ed.). Teachers College Press, 1234 Amsterdam Avenue.

Shetty, S., Shilpa, C., Dey, D., \& Kavya, S. (2020). Academic Crisis During COVID 19: Online Classes, a Panacea for Imminent Doctors. Indian Journal of Otolaryngology and Head and Neck Surgery. https://doi.org/10.1007/s12070-020-02224-x

Shin, J. Y., Nhan, N. V., Lee, S. B., Crittenden, K. S., Flory, M., \& Hong, H. T. D. (2009). The effects of a home-based intervention for young children with intellectual disabilities in Vietnam. Journal of Intellectual Disability Research, 53(4), 339-352. https://doi.org/10.1111/j.1365-2788.2008.01151.x

Thakur, A. (2020). Mental Health in High School Students at the Time of COVID-19: A Student's Perspective. In Journal of the American Academy of Child and Adolescent Psychiatry (Vol. 59, Issue 12, pp. 1309-1310). Elsevier Inc. https://doi.org/10.1016/j.jaac.2020.08.005

Thorell, L. B., Skoglund, C., de la Peña, A. G., Baeyens, D., Fuermaier, A. B. M., Groom, M. J., Mammarella, I. C., van der Oord, S., van den Hoofdakker, B. J., Luman, M., de Miranda, D. M., Siu, A. F. Y., Steinmayr, R., Idrees, I., Soares, L. S., Sörlin, M., 
Luque, J. L., Moscardino, U. M., Roch, M., ... Christiansen, H. (2021). Parental experiences of homeschooling during the COVID-19 pandemic: differences between seven European countries and between children with and without mental health conditions. European Child and Adolescent Psychiatry, 0123456789. https://doi.org/10.1007/s00787-020-01706-1

Toquero, C. M. D. (2021). 'Sana All' Inclusive Education amid COVID-19: Challenges, Strategies, and Prospects of Special Education Teachers. International and Multidisciplinary Journal of Social Sciences, $10(1)$. https://doi.org/10.17583/rimcis.2020.6316

Unni, J. C. (2020). Social Effects of COVID-19 Pandemic on Children in India. Indian Pediatrics, 57(12), 1107. https://doi.org/10.1007/s13312-020-2060-y

Vaughn, S., \& Swanson, E. A. (2015). Special education research advances knowledge in education. Exceptional Children, 82(1), 11-24. https:// doi.org/10.1177/0014402915598781

Viner, R. M., Russell, S. J., Croker, H., Packer, J., Ward, J., Stansfield, C., Mytton, O., Bonell, C., \& Booy, R. (2020). School closure and management practices during coronavirus outbreaks including COVID-19: a rapid systematic review. The Lancet Child and Adolescent Health, 4(5), 397-404. https://doi.org/10.1016/S23524642(20)30095-X

WHO. (2020). Disability considerations during the COVID-19 outbreak. World Health Organization, 10(1). https://doi.org/10.46945/bpj.10.1.04.07 